\title{
Fgfr1 regulates patterning of the pharyngeal region
}

\author{
Nina Trokovic, Ras Trokovic, Petra Mai, and Juha Partanen ${ }^{1}$ \\ Institute of Biotechnology, Viikki Biocenter, 00014-University of Helsinki, Finland
}

\begin{abstract}
Development of the pharyngeal region depends on the interaction and integration of different cell populations, including surface ectoderm, foregut endoderm, paraxial mesoderm, and neural crest. Mice homozygous for a hypomorphic allele of Fgfr1 have craniofacial defects, some of which appeared to result from a failure in the early development of the second branchial arch. A stream of neural crest cells was found to originate from the rhombomere 4 region and migrate toward the second branchial arch in the mutants. Neural crest cells mostly failed to enter the second arch, however, but accumulated in a region proximal to it. Both rescue of the hypomorphic Fgfr1 allele and inactivation of a conditional Fgfr1 allele specifically in neural crest cells indicated that Fgfr1 regulates the entry of neural crest cells into the second branchial arch non-cellautonomously. Gene expression in the pharyngeal ectoderm overlying the developing second branchial arch was affected in the hypomorphic Fgfr1 mutants at a stage prior to neural crest entry. Our results indicate that Fgfr1 patterns the pharyngeal region to create a permissive environment for neural crest cell migration.
\end{abstract}

[Keywords: Craniofacial development; fibroblast growth factor; branchial arch; hindbrain; neural crest; cell migration; cleft palate; Cre recombinase]

Supplemental material is available at http://www.genesdev.org.

Received October 1, 2002; revised version accepted October 17, 2002.

Branchial arches of vertebrate embryos are transient structures that give rise to various elements of lower face, pharynx, as well as outer and middle ear. Cells from all three germ layers contribute to the development of the branchial arches. Each branchial arch contains a central blood vessel, the aortic arch, surrounded by cells of paraxial mesoderm. This mesodermal core is in turn encapsulated in the neural crest cells located at more peripheral regions of the arch. The inner surface of the arches is composed of the cells of pharyngeal endoderm and the outer surface of the ectoderm. Relatively little is known about the early processes that coordinate the development of the different components of these complex structures. Traditionally, the neural crest cells, which give rise to the skeletal elements derived from the arches, have been thought to have an instrumental role in branchial arch patterning. Recent evidence, however, also points to neural-crest-independent mechanisms of pharyngeal development (Graham 2001).

Before the formation of the branchial arches themselves, the mid- and hindbrain acquire their antero-posterior identity and start expressing positional determinants. These include Hox genes, which are expressed in segmental domains of hindbrain, called rhombomeres

${ }^{1}$ Corresponding author.

E-MAIL Juha.M.Partanen@Helsinki.Fi; FAX 358-9-191-59366.

Article and publication are at http://www.genesdev.org/cgi/doi/10.1101/ $\operatorname{gad} .250703$.
(Lumsden and Krumlauf 1996; Rijli et al. 1998). The most dorsal neural tube gives rise to a mesenchymal cell population, the neural crest. Hindbrain-derived neural crest cells mostly retain the Hox-encoded antero-posterior identity of the rhombomeric level, from where they originate. Hox gene expression, however, appears to be regulated by different molecular mechanisms in the neuroepithelium of the hindbrain and in the neural crest cells (Maconochie et al. 1999) and environmental signals are important for the maintenance of Hox expression in the neural crest (Trainor and Krumlauf 2000; see below). The neural crest cells migrate ventrally as separate streams and participate in the development of segmental structures of the branchial arches. Some of the molecular mechanisms regulating neural crest migration have been identified. Ephrins and their receptors are involved in the guidance of the neural crest cells into the proper branchial arches (Smith et al. 1997). In addition, fibroblast growth factors (FGFs) have been shown to be chemotactic for neural crest cells (Kubota and Ito 2000) and may therefore regulate their migration into the arches.

As described above, mesodermal, ectodermal and endodermal cells also contribute to the branchial arches. Recent evidence suggests that the cell types other than neural crest have a great impact on the development and patterning of the pharyngeal region. In fact, initial development of the branchial arches can take place even in the absence of neural crest (Veitch et al. 1999). Surrounding tissues also affect the type of skeletal elements that 
develop from the neural crest cells. Transplantation studies in avian embryos have demonstrated the importance of regionalization in the pharyngeal endoderm for the neural crest patterning (Couly et al. 2002). The cranial mesoderm, in turn, has been shown to be able to maintain the appropriate Hox gene expression in the adjacent neural crest cells (Trainor and Krumlauf 2000). Also, the pharyngeal ectoderm, which has been suggested to be divided into domains called ectomeres (Couly and Le Douarin 1990), is an important source of signals regulating branchial arch development (Richman and Tickle 1989; Tucker et al. 1999; Veitch et al. 1999). The signaling molecules expressed in distinct regions of the branchial ectoderm and endoderm include Endothelins, Bone Morphogenetic Proteins, Wnt family members, Sonic Hedgehog, and several members of the FGF family (Francis-West et al. 1998). FGFs have been shown to affect outgrowth and patterning of the neural crest cells in branchial arch explant cultures (Tucker et al. 1999; Ferguson et al. 2000). In addition, using tissuespecific gene inactivation in mice, it was demonstrated that FGF8 supports survival of the neural crest cells in the mandibular arch (Trumpp et al. 1999). The mechanisms that pattern the nonneural crest tissues of the pharyngeal region and define the regions where epithelial signaling centers form, however, are poorly understood.

We have studied the functions of FGF signaling during pharyngeal development. The effects of FGFs are mediated by four tyrosine kinase-type receptors, FGFR1FGFR4, expressed on the surface of the target cells. Mouse embryos homozygous for a null mutation in the Fgfr1 gene are unable to gastrulate normally and die during early gestation (Deng et al. 1994; Yamaguchi et al. 1994;). Fgfr1 is widely expressed also during later development, indicating additional functions. In the pharyngeal region, Fgfr1 is expressed in different cellular components of the branchial arches, and may therefore have multiple roles during the development of the arches and their derivatives (Yamaguchi et al. 1992; Wilke et al. 1997). We have used hypomorphic (partial loss-of-function) and conditional alleles of the Fgfr1 gene here to study the role of FGF signaling in the pharyngeal development. Our results show that FGFR1 is required for the entry of neural crest cells into the second branchial arch. The defect in neural crest cell migration, however, is not cell-autonomous, but appears to result from early mispatterning of the pharyngeal region in the hypomorphic Fgfr1 mutants.

\section{Results}

Craniofacial defects in the newborn hypomorphic Fgfr1 mutants

Fgfr1 is widely expressed in various cellular components of the branchial arches throughout their development (see Supplemental Material). Mice homozygous for hypomorphic alleles of the Fgfr1 gene, $F g f r 1^{n 7}$, and $F g f r 1^{n 15}$ (Partanen et al. 1998) die neonatally and have craniofacial defects, including greatly reduced size of the pinna of the outer ear (Fig. 1A,B). Because the Fgfr1 1 15/n15 embryos are often growth-retarded, the $F g f r 1^{n 7 / n 7} \mathrm{mu}-$ tants were used in this study for the further studies of the craniofacial defects. The Fgfr $1^{n 7}$ allele carries a neocassette insertion in intron 7. As a result, the amount of full-length Fgfr1 transcript produced by $F g f r 1^{n 7}$ allele is only $\sim 20 \%$ of the wild-type levels (Partanen et al. 1998).

We analyzed skeletal preparations $(\mathrm{n}=23)$ of newborn Fgfr $1^{n 7 / n 7}$ mice and found several abnormalities in the cranial bones and cartilages (Fig. 1C-J, Table 1). The retrotympanic process of the squamosal bone was affected in all of the mutants (Fig. 1C,D,G,H), and the posterior part of the alisphenoid bone was malformed (Fig. 1E,F). Also, the tympanic rings were defective or absent (Fig. $1 \mathrm{C}-\mathrm{F})$. Open palatine shelves were observed in $80 \%$ of the Fgfr $1^{n 7 / n 7}$ mutants (Fig. 1E). The cleft palate may have resulted from a block in palatal shelf elevation caused by the tongue, which in histological sections was still observed in between the palatal shelves at E16.5 (data not shown). The size of the mandible itself appeared normal (Fig. 1C,D). Variable deficiencies were observed in the middle ear ossicles. In the least severe cases, only the proximal part of the styloid process was affected. The more severely affected $F g f r 1^{n 7 / n 7}$ mutants lacked most of the middle ear ossicles (Fig. 1H). The lesser horns of the hyoid bone were present but abnormal in orientation (Fig. 1I,J). In summary, both chondrocranial and dermatocranial derivatives of the first and second branchial arches were affected in $F g f r 1^{n 7 / n 7}$ mice (see Table 1).

\section{Branchial arch morphology of the Fgfr $1^{\mathrm{n} 7 / \mathrm{n} 7}$ embryos}

As most of the affected skeletal elements were derived from the branchial arch neural crest cells, we analyzed the early development of the branchial arches in the Fofr $1^{n 7 / n 7}$ mutants. The second branchial arch was found to be abnormal from the earliest stages of its development (Fig. 3, below). At E9.5, the second arch was either almost completely missing (Fig. 2A,B) or its proximal part was reduced in size. At E10.5, the proximal region of the second arch was barely visible (Fig. 2C,D). The distal region was often still present but was not connected to the proximal region. Interestingly, the early stages of development of the first and third arches appeared relatively normal despite the abnormalities seen in many of the skeletal elements derived from the first arch. To visualize the endothelial cells of the aortic arches we crossed the Fgfr $1^{n 7 /+}$ mice with Tie $1^{1 c Z /+}$ mice carrying LacZ gene insertion in the Tie1 locus (Puri et al. 1995). $\beta$-Galactosidase staining of the Fgfr $1^{n 7 / n 7}$; Tie $1^{1 c Z /+}$ embryos revealed severe and specific defect in the development of the second aortic arch (Fig. 2E,F).

\section{Hindbrain segmentation and patterning in the Fgfr $1^{\mathrm{n} 7 / \mathrm{n} 7}$ embryos}

We next wanted to understand what process in the second branchial arch development was affected in the 

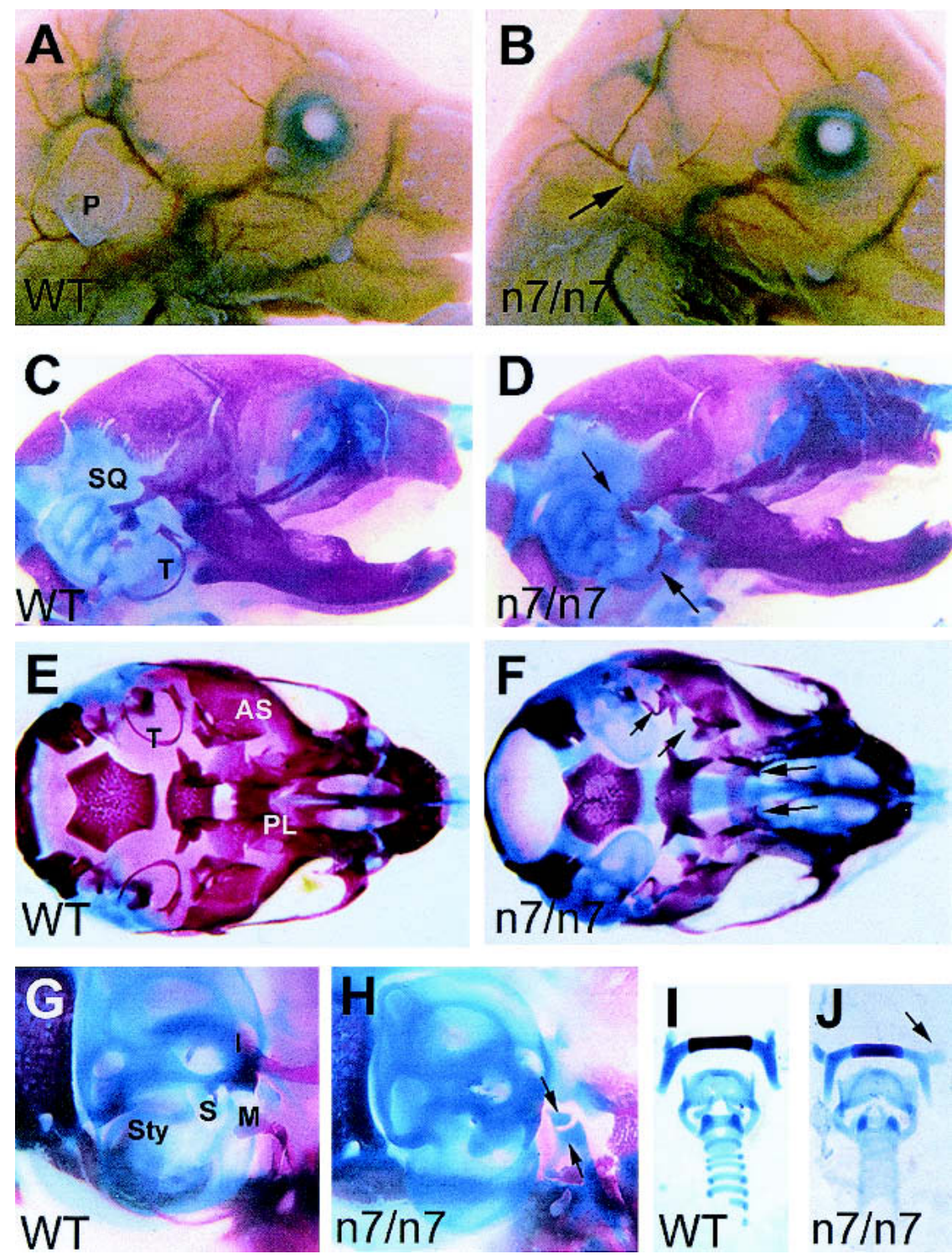

Figure 1. Craniofacial defects in newborn Fgfr $1^{n 7 / n 7}$ hypomorphic mutants. Side views of newborn wild-type $(A)$ and $F g f r 1^{n 7 / n 7}(B)$ heads. Arrow in $B$ indicates the pinna of the outer ear, which is significantly reduced in the mutant. Side views of wild-type $(C)$ and $F g f r 1^{n 7 / n 7}(D)$ skulls. Note the normal size of the skull and mandible of the mutant. The posterior part of the squamosal bone (SQ) fails to form the retrotympanic recess and tympanic rings (T) are reduced or missing in the mutant (arrows in $D$ ). Ventral views of wild-type $(E)$ and $F g f r 1^{n 7 / n 7}(F)$ skulls, after removal of the lower jaw. Alisphenoid bone (AS), palatine $(\mathrm{PL})$, and tympanic ring $(\mathrm{T})$ are indicated in the wild type. The mutant in $F$ has a cleft palate, a malformed posterior part of the alisphenoid bones and reduced tympanic rings (arrows). Side views of wildtype $(G)$ and mutant $(H)$ middle ears. Styloid process (Sty), stapes (S), incus (I), and malleus $(\mathrm{M})$ are indicated in the wild type. The mutant $(H)$ lacks distinguishable middle ear ossicles. The arrows in $H$ point at remaining cartilage condensations at the end of the Meckel's cartilage. Dissected hyoid bone and laryngeal cartilages from wild-type $(I)$ and $F g f r 1^{n 7 / n 7}(J)$ mice. Note the abnormal orientation of the lesser horns of the hyoid bone in mutant (arrow in $J$ ).
Fgfr $1^{n 7 / n 7}$ mutants. Fgfr1 is involved in the antero-posterior patterning of the somitic mesoderm, and FGF signaling has also been suggested to pattern the neuroectoderm. Furthermore, Hoxa1/Hoxb1 compound mutants display defects in the development of the second branchial arch (Gavalas et al. 1998), which are somewhat similar to the phenotype in the $F g f r 1^{n 7 / n 7}$ mutants. Therefore, we analyzed whether the antero-posterior patterning of the hindbrain or its neural crest derivatives was affected in the $F g f r 1^{n 7 / n 7}$ mice. No significant differences in the expression of regional markers Krox20, Hoxd4, Hoxb1, Hoxb2, and EphA4 in the hindbrain were detected between wild-type and $F g f r 1^{n 7 / n 7}$ embryos at E8.5-E9.5 (Fig. 3). In addition to its unaltered expression in the hindbrain, Hoxb2 was still expressed in the remaining second arch neural crest in the mutants.
Generation, migration, and patterning of neural crest cells in Fgfr $1^{\mathrm{n} 7 / \mathrm{n} 7}$ embryos

We then analyzed whether neural crest of the second branchial arch was correctly generated at the dorsal hindbrain and whether it migrated normally toward the second branchial arch in the Fgfr $1^{n 7 / n 7}$ mutants. The neural crest cells were visualized in E9.0-E9.5 Fgfr $1^{n 7 / n 7}$ and wild-type embryos by whole-mount in situ hybridization using Crabp1, Ap2, and Hoxa2, probes (Fig. 4). Streams of neural crest cells were found to originate from the dorsal rhombomere 4 and the ventral migration of the neural crest cells toward the second branchial arch appeared undisturbed in the Fgfr $1^{n 7 / n 7}$ embryos. The second arch neural crest cells still expressed EphB3 (data not shown) and no mis- or rerouting of the neural crest was evident in the $F g f r 1^{n 7 / n 7}$ mutants. Only few neural 
Trokovic et al.

Table 1. Abnormalities of branchial arch derived skeletal elements in the Fgfr1 mutants

\begin{tabular}{|c|c|c|c|}
\hline \multirow[b]{2}{*}{ Skeletal element } & \multicolumn{3}{|c|}{ Genotype } \\
\hline & $\operatorname{Fgfr} 1^{n 7 / n 7}(\mathrm{n}=23)$ & $\begin{array}{c}\text { Wnt1-Cre/+; Fgfr1 } 1^{n 7 / n 7} \\
(\mathrm{n}=8)\end{array}$ & $\begin{array}{l}\text { Wnt1-Cre/+; } \\
\text { Fgfr flox } / \text { flox } \\
(\mathrm{n}=11)\end{array}$ \\
\hline \multicolumn{4}{|l|}{$1^{\text {st }} \mathrm{ARCH}$} \\
\hline palatine & open (in $80 \%$ ) & closed & open \\
\hline pterygoid & flattened (in $80 \%$; correlates with cleft palate) & normal & flattened \\
\hline alisphenoid & posterior part always affected & posterior part always affected & normal \\
\hline squamosum & posterior part always affected & posterior part always affected & normal \\
\hline incus & variable deficiencies & variable deficiencies & normal \\
\hline malleus & variable deficiencies & variable deficiencies & normal \\
\hline tympanic ring and gonial & reduced or absent & reduced & normal \\
\hline \multicolumn{4}{|l|}{$2^{\text {nd }} \mathrm{ARCH}$} \\
\hline lesser horn of hyoid bone & point laterally (in $80 \%$; correlates with cleft palate) & normal & point laterally \\
\hline stapes & deficient or missing & deficient or missing & normal \\
\hline styloid process & proximal part always missing & proximal part always missing & normal \\
\hline
\end{tabular}

crest cells, however, were detected in the second branchial arch itself. Interestingly, more neural crest cells were observed anterior to the otic vesicle in a region next to the second branchial arch in the $F g f r 1^{n 7 / n 7}$ mutants compared with the wild-type embryos. These results indicate that neural crest cells fail to enter the second branchial arch but accumulate at a site proximal to the arch in the $F g f r 1^{n 7 / n 7}$ embryos. At E10.5, the connection between the distal arch and the dorsal pharyngeal region was disrupted. This argues against the possibility of delayed migration of neural crest cells into the second branchial arch at later stages.

Proximo-distal patterning of the second branchial arch of the $F g f r 1^{17 / n 7}$ mutants was analyzed using Dlx1, Dlx2, Dlx5, and Msx1 probes (Fig. 5). At E9.5, Dlx1 and Dlx2 were found to be still expressed in the remnants of the proximal second branchial arch and all Dlx1,Dlx2, and Dlx5 were expressed in the distal second arch of the Fgfr ${ }^{177 / n 7}$ mutants (Fig. 5B,F,J,). Therefore, no defect in the proximo-distal patterning of the second branchial arch was detected at this stage. At E10.5, Dlx1, Dlx2, $D l \times 5$, and Msx1 were still expressed in the distal arch, but no expression could be detected in the proximal region (Fig. 5D,H,L,N). This could reflect altered identity or apoptotic death of the cells failing to enter the arch (see below).

\section{Neural crest cell death in the Fgfr ${ }^{\mathrm{n} 7 / \mathrm{n} 7}$ embryos}

To determine the fate of the second arch neural crest cells, we analyzed cell death in the branchial region at E9.5 by whole-mount Nile blue staining. Strong signal was detected in $F g f r 1^{n 7 / n 7}$ embryos $(\mathrm{n}=5)$ in a proximal region next to the second branchial arch (Fig. 6A,B). This region corresponds to the site where second arch neural crest cells were seen to accumulate in the mutants (Fig. 4). We also observed increased neural crest cell apoptosis proximal to the second branchial arch in the $F g f r 1^{n 7 / n 7}$ embryos by TUNEL staining (Fig. 6C-E). In contrast, no abundant cell death was detected in the second arch itself (Fig. 6B; data not shown).
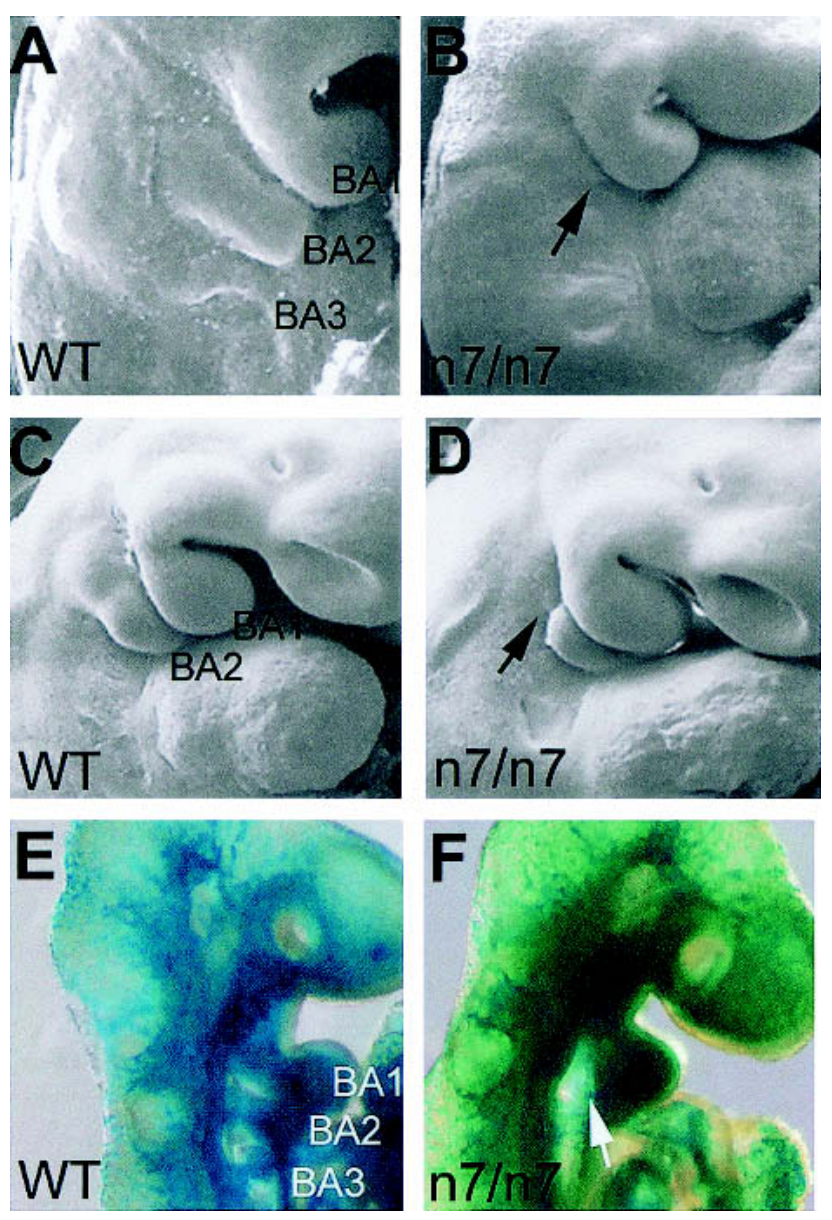

Figure 2. Morphology of the second branchial arch in Fgfr $1^{n 7 / n 7}$ mutants. Scanning electron micrographs of the wild-type control $(A, C)$ and mutant embryos $(B, D)$ at E9.5 $(A, B)$ and E10.5 $(C, D)$. Aortic arches were visualized by whole-mount $\beta$-galactosidase staining of E9.5 Fgfr ${ }^{+/+} ;$Tie $^{1 c Z /+}(E)$ and $F g f r 1^{n 7 / n 7}$; Tie $1^{1 c Z /+}(F)$ embryos. $(B, D, F)$ Arrows indicate proximal region of the second branchial arch in mutants. BA1-3, branchial arch 1-3. 


\section{Krox20/Hoxd4}
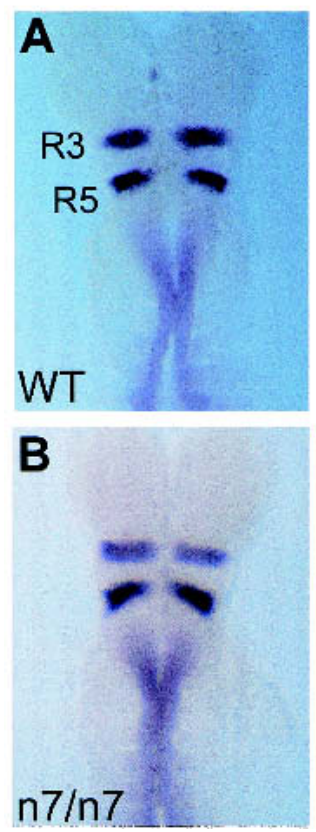

Hoxb1
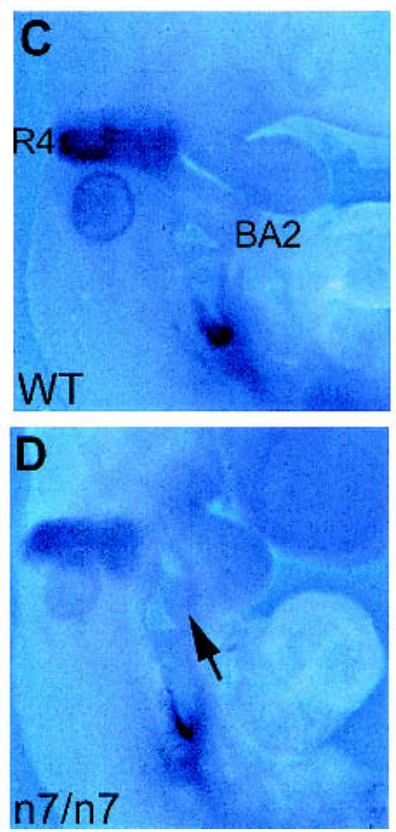

Hoxb2
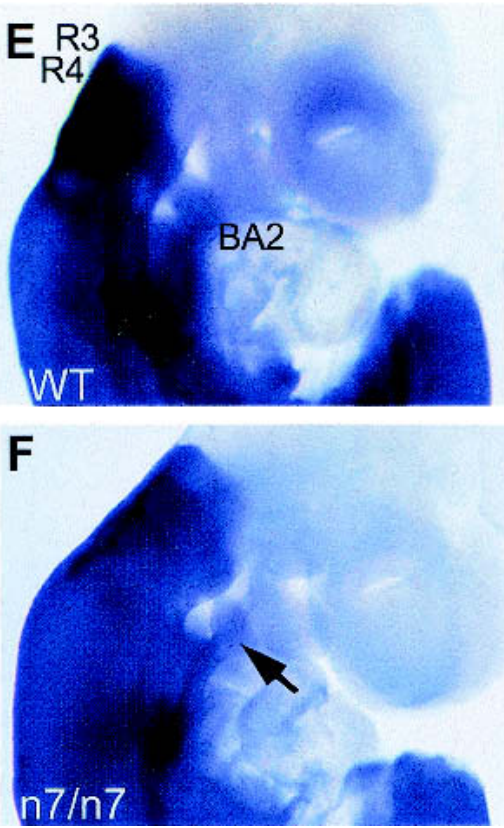

EphA4
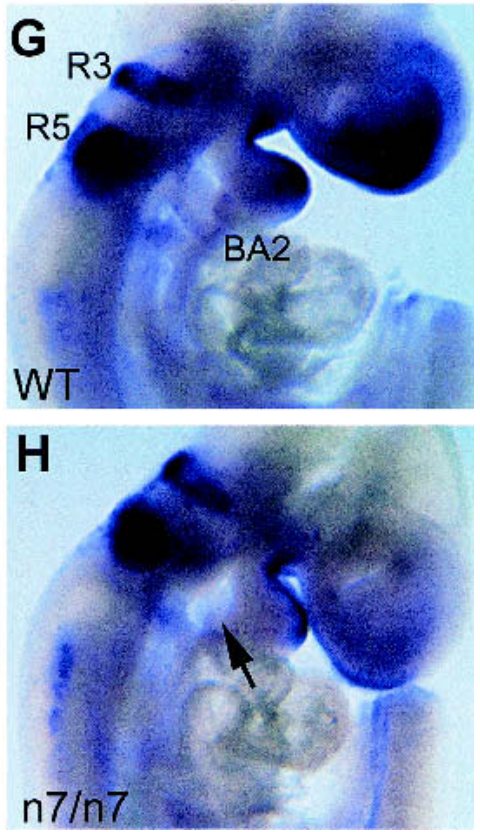

Figure 3. Hindbrain segmentation and patterning in the $F g f r 1^{n 7 / n 7}$ mutants. Whole-mount mRNA in situ hybridization analysis of the expression of molecular markers for the hindbrain segmentation in wild-type $(A, C, E, G)$ and $F g f r 1^{n 7 / n 7}$ mutant $(B, D, F, H)$ embryos. Dorsal views of E8.5 embryos hybridized with the Krox20 and Hoxd4 probes $(A, B)$. Side views of E9.5 embryos hybridized with Hoxb1 $(C, D), H o x b 2(E, F)$, and EphA4 $(G, H)$ probes. $(D, F, H)$ Arrows indicate affected second branchial arch in mutants. $(A-H)$ Note the similar gene expression patterns in wild-type and $F g f r 1^{n 7 / n 7}$ embryos. R3-5, rhombomere 3-5; BA2, second branchial arch.

\section{Neural crest cell-specific rescue and mutation of Fgfr1}

To determine whether Fgfr1 is required in the neural crest cells themselves for their migration, we wanted to inactivate Fgfr1 tissue-specifically in the neural crest. For this purpose we used a conditional allele, Fgfr1 ${ }^{\text {flox }}$ (R.
Trokovic, N. Trokovic, S. Hernesniemi, U. Pirvola, J. Rossant, A.P. McMahon, W. Wurst, and J. Partanen, in prep.), which can be inactivated by the Cre recombinase, and a Wnt1-Cre transgene driving Cre expression in the neural crest precursors (Danielian et al. 1998). We first crossed the Wnt1-Cre mice with a Z/AP reporter line
Crabp1

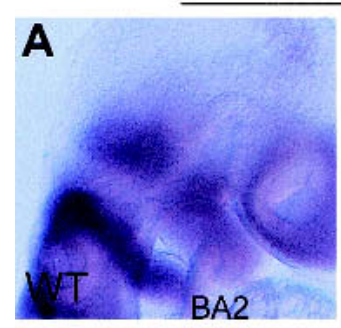

B

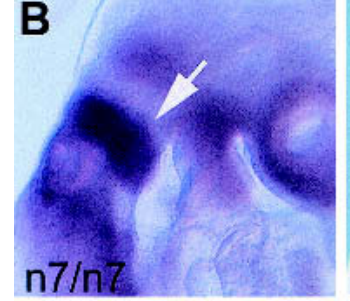

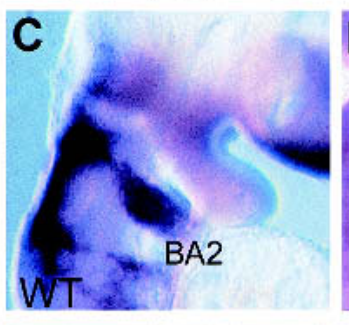

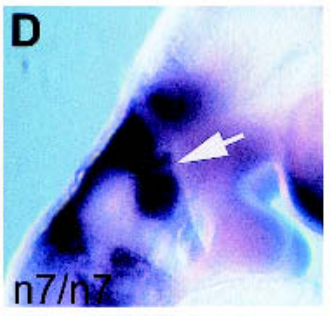

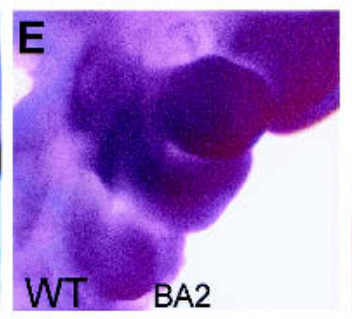

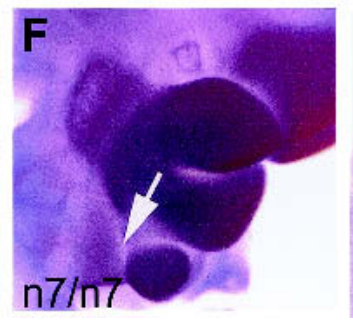

Ap2
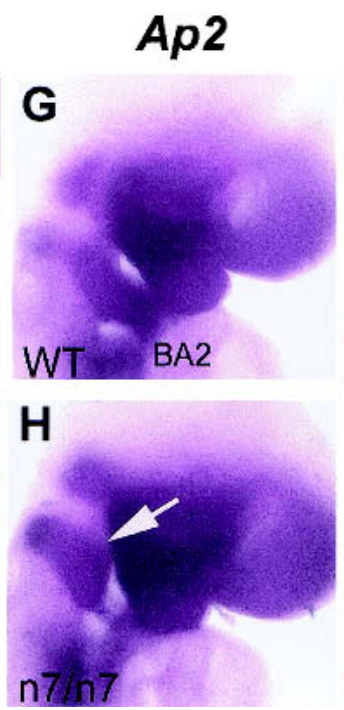

Hoxa2
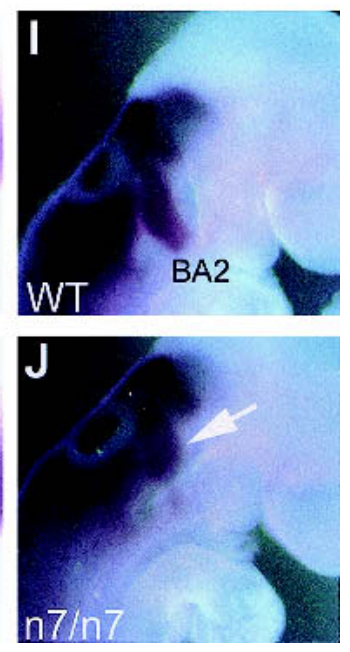

Figure 4. Generation and migration of branchial arch neural crest cells in $F g f r 1^{n 7 / n 7}$ mutants. Neural crest cells were detected by whole-mount mRNA in situ hybridization using Crabp1 $(A-F), A p 2(G, H)$, and Hoxa2 $(I, I)$ probes. Side views of E9 $(A, B, G-J)$, E9.5 $(C, D)$, and E10.5 $(E, F)$ embryos. $(B, D, F, H, J)$ Note that in $F g f r 1^{n 7 / n 7}$ mutants, abundant neural crest cells migrate out from the rhombomere 4 region, but they accumulate in front of the second branchial arch (arrows) and mostly fail to populate the arch. 


\section{$D / x 1$}
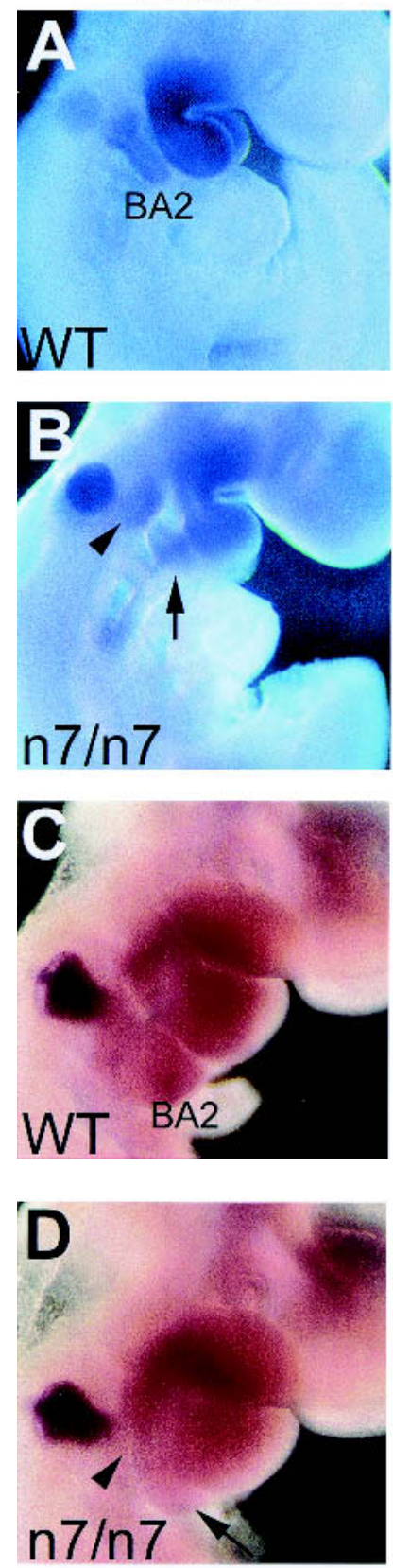

DIx2
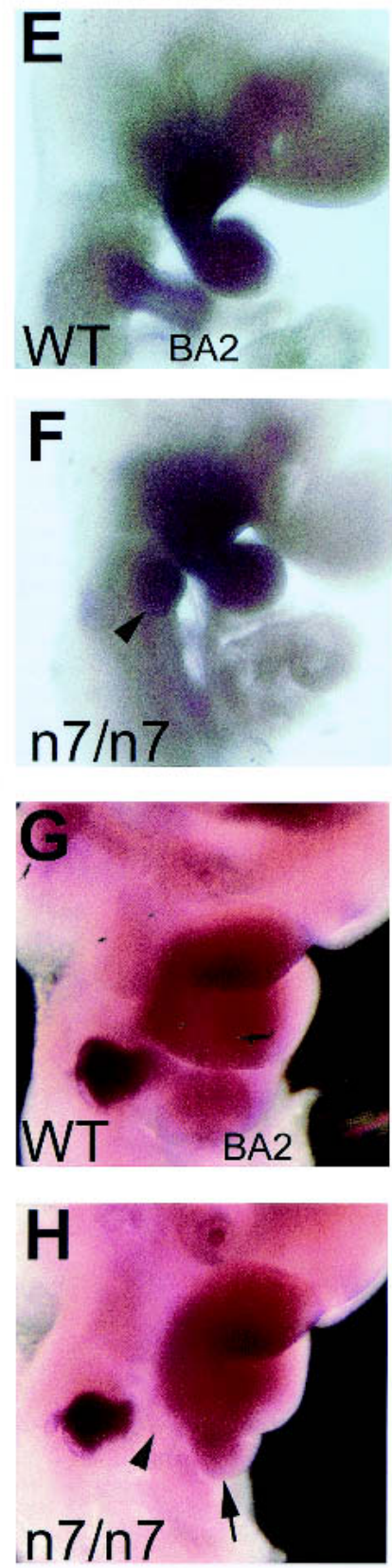

D/x5
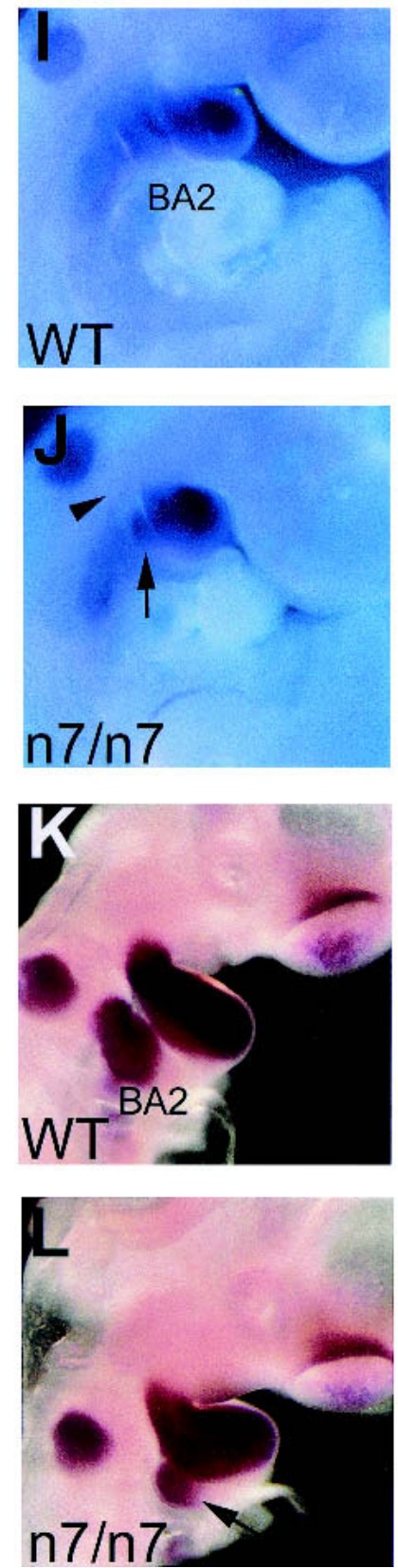
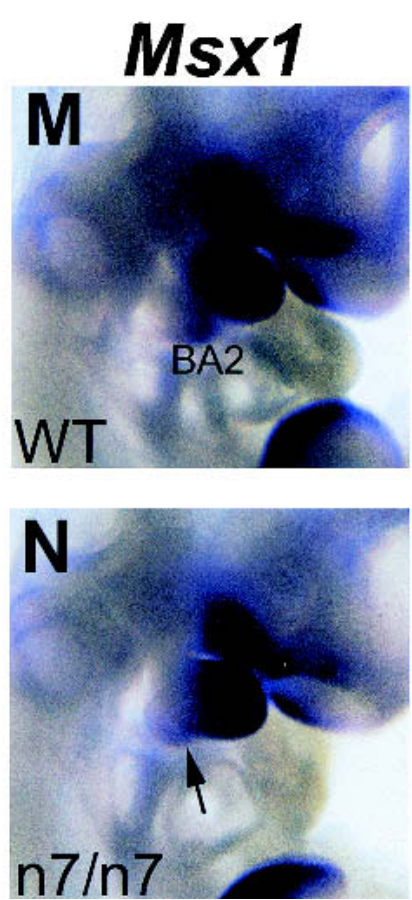

Figure 5. Proximo-distal patterning of the second branchial arch in $F g f r 1^{n 7 / n 7}$ mutants. Whole-mount in situ hybridization analysis of the expression of Dlx1 $(A-D), D l \times 2(E-H), D l x 5(I-L)$, and $M s \times 1(M, N)$ at E9.5 $(A, B, E, F, I, J)$ and E10.5 $(C, D, G, H, K, L, M, N)$. At E9.5, the patterns of gene-expression in the neural crest of the proximal and distal second branchial arch are similar in wild-type $(A, E, I)$ and $F g f r 1^{n 7 / n 7}(B, F, J)$ embryos. At E10.5, the distal second branchial arch of both the wild-type $(C, G, K, M)$ and $F g f r 1^{n 7 / n 7}(D, H, L, N)$ embryos expresses all the genes analyzed. $(D, H, L, N)$ In contrast, no expression of $D l x 1$ and Dlx2 can be detected in the proximal second branchial arch region in $F g f r 1^{n 7 / n 7}$ embryos. Arrows mark the distal second arch, arrowhead the proximal region. BA2, second branchial arch.

(Lobe et al. 1999) to analyze the pattern of Cre activity expressed by the Wnt1-Cre transgene. In the resulting Wnt1-Cre/+; Z/AP/+ embryos the effects of Cre mediated recombination on reporter gene expression could be observed already in the migrating neural crest cells well before their entry to the second arch (Fig. 7A; data not shown). Therefore, we next generated Wnt1-Cre/+; Fgfr1 $1^{\text {flox/flox }}$ embryos (Fig. 7F-I). Fgfr1 expression was efficiently inactivated in the neural crest cells of these embryos (Fig. 7C,D,G,H). No defects, however, were observed in the early development of the second branchial arch in the Wnt1-Cre/+; Fgfr $1^{\text {flox/flox }}$ embryos at E9.5 


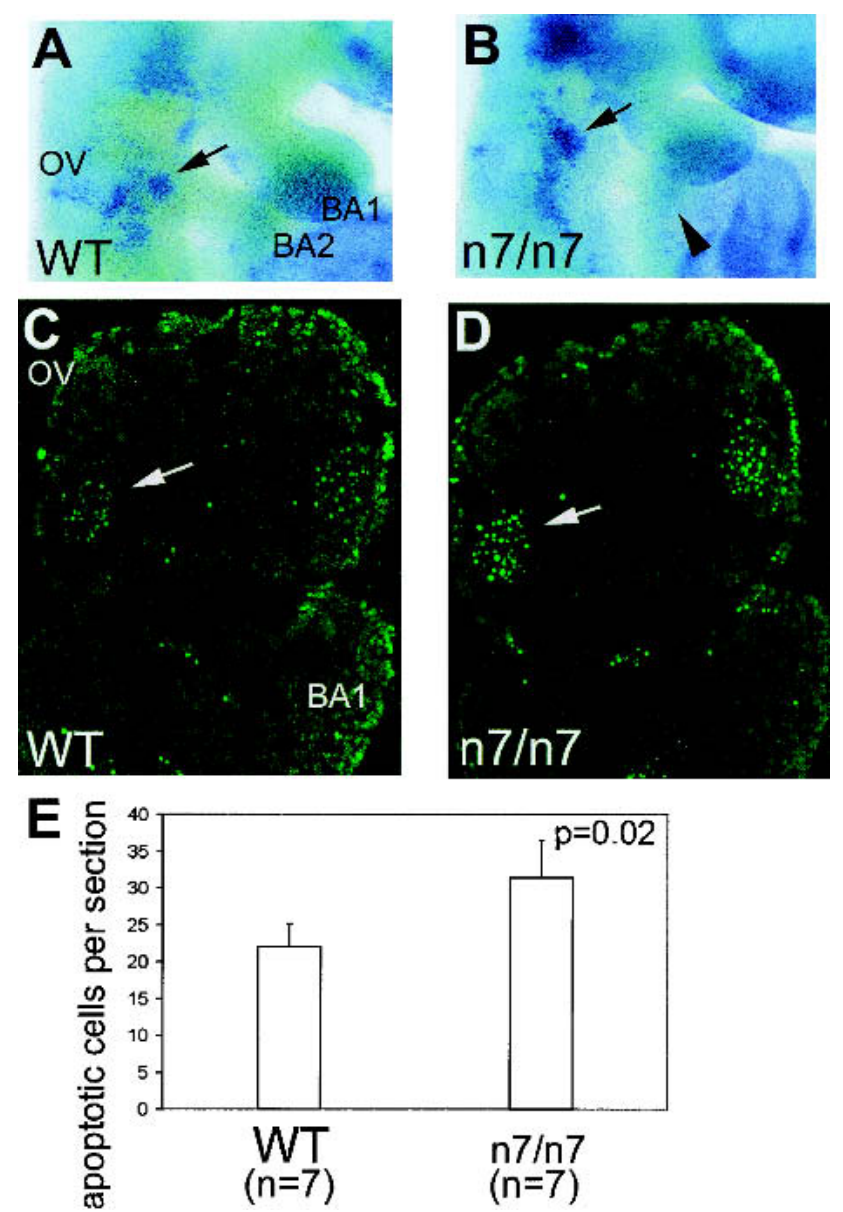

Figure 6. Analysis of cell death in $F g f r 1^{n 7 / n 7}$ mutants. Detection of apoptotic cells by Nile blue sulfate (NBS) staining $(A, B)$ and TUNEL staining $(C, D)$ on sections in E9.5 wild-type $(A, C)$ and $F g f r 1^{n 7 / n 7}(B, D)$ embryos. Cell death, proximally to the second branchial arch (indicated by arrows in $A-D$ ), is significantly increased in $F g f r 1^{n 7 / n 7}$ mutants $(B, D)$. $(E)$ The number of apoptotic mesenchymal cells, counted from sections of the second branchial arch region of wild-type and $F g f r 1^{n 7 / n 7}$ embryos, is presented graphically. BA1, first branchial arch; BA2, second branchial arch; OV, otic vesicle.

(Fig. 7G). Interestingly, a number of other defects in craniofacial development, including cleft palate, were observed in skeletal preparations of Wnt1-Cre/+; Fgfr1 ${ }^{\text {flox } / ~}$ flox newborns (Fig. 7I; Supplemental Material).

We also generated Wnt1-Cre/+; Fgfr $1^{\Delta \text { flox/flox }}$ embryos carrying one conditional and one null allele of Fgfr1. In these mice a single Cre-mediated recombination event is enough to inactivate Fgfr1 function in the target cell. Development of the second branchial arch was still normal in the Wnt1-Cre/+; Fgfr1 ${ }^{\Delta \text { flox/flox }}$ embryos (data not shown). In addition, the expressivity of the late craniofacial phenotypes were not enhanced in Wnt1-Cre/+; Fgfr1 $1^{\Delta \text { flox } / \text { flox }}$ compared with Wnt1-Cre/+; Fgfr1 $1^{\text {flox/flox }}$ mutants, further suggesting efficient inactivation of Fgfr $1^{\text {flox }}$ by Wnt1-Cre. These results indicated that the second branchial arch defects in the $F g f r 1^{n 7 / n 7}$ were at- tributable to Fgfr1 function in a cell type other than neural crest.

To test this hypothesis further, we wanted to restore normal Fgfr1 function specifically in the neural crest cells of the $F g f r 1^{n 7 / n 7}$ embryos. The reduced gene expression by the Fgfr $1^{n 7}$ allele is caused by a neo-cassette insertion in the intron 7 . The neo-cassette is flanked by loxP sites, which allow excision of the cassette by the Cre recombinase. This results in the allele Fgfr $1^{17}$, which appears to be functionally equal to a wild-type allele. To convert the hypomorphic Fgfr $1^{n 7}$ allele into $F g f r 1^{17}$ specifically in the neural crest cells, we generated Wnt1-Cre/+; Fgfr1 $1^{n 7 / n 7}$ embryos (Fig. 7J-L). At E9.5, these embryos showed disruption of the second branchial arch development comparable with the Fgfr $1^{n 7 / n 7}$ embryos (Fig. 7K). Some other defects, such as palatal clefting, were rescued in all Wnt1-Cre/+; Fgfr $1^{n 7 / n 7} \mathrm{mu}-$ tants analyzed (Fig. 7L; Supplemental Material). In summary, the results of both neural-crest-specific mutation and neural-crest-specific rescue experiment argue against a neural-crest-cell-specific function for Fgfr1 during second branchial arch development.

\section{Patterning of the pharyngeal epithelium in the Fgfr $1^{\mathrm{n} 7 / \mathrm{n} 7}$ mutants}

The tissue-specific mutagenesis and rescue experiments indicated that the primary defect was not in the neural crest cells themselves. Therefore, we wanted to analyze patterning of the pharyngeal epithelia in the $F g f r 1^{n 7 / n 7}$ mutants. For this, we studied expression of regional markers Fgf3, Fgf8, Pax1, and Bmp4 at E9 (Fig. 8). In wild-type embryos Fgf8 was detected in the proximorostral and proximo-caudal epithelial borders of all branchial arches (Fig. 8A; Heikinheimo et al. 1994; Crossley and Martin 1995). This distinct pattern of Fgf8 expression could not be observed specifically in the second branchial arch of $F g f r 1^{n 7 / n 7}$ mutants (Fig. 8B). Normal domain of $F g f 3$ expression in the rostral ectodermal and endodermal margins of the second and third arch (Fig. 8C; Wilkinson et al. 1988; Mahmood et al. 1996) was shifted caudally in the remaining second branchial arch in $F g f r 1^{n 7 / n 7}$ hypomorphs, whereas it was not affected in the third arch (Fig. 8D). Expression of Pax1, which is a specific marker for endodermally derived pharyngeal pouches (Fig. 8E; Muller et al. 1996), was expanded to cover also the region in between the first and second pharyngeal pouches lining the second branchial arch (Fig. 8F). Also Bmp4, which in wild-type embryos was detected in the dorsal first pharyngeal pouch (Fig. 8G), extended its expression domain to the second branchial arch region (Fig. $8 \mathrm{H}$ ). Therefore, our results show that hypomorphic mutation of Fgfrl affects patterning of the pharyngeal epithelia in the region of proximal second branchial arch.

The observed changes in epithelial gene expression could secondarily result from a failure in neural crest migration and proper second arch formation. Alternatively, a defect in the patterning of the pharyngeal epithelia could result in abnormal behavior of the neural 

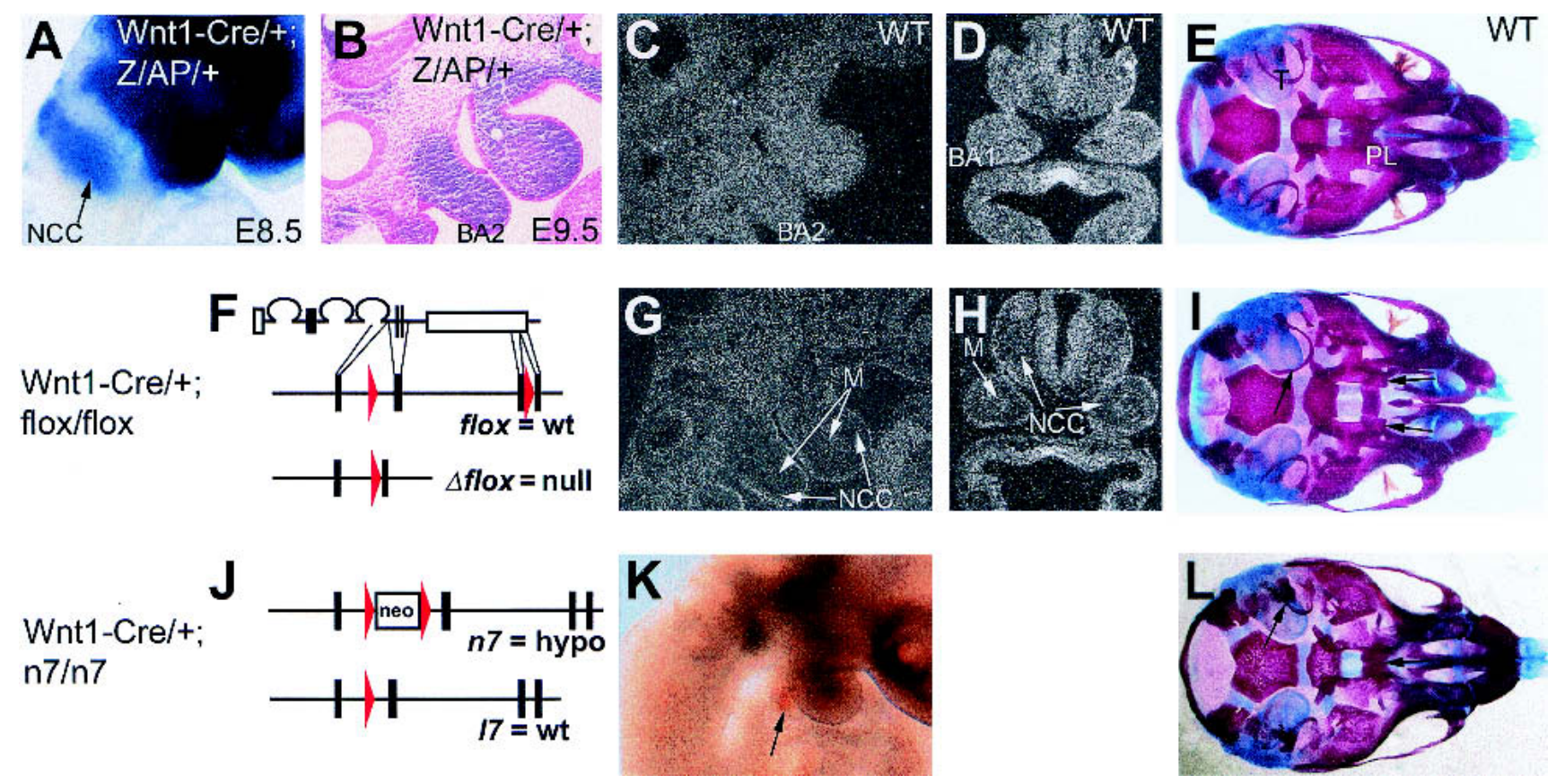

Figure 7. Neural-crest-cell-specific inactivation and rescue of Fgfr1. Alkaline phosphatase staining of E8.5 (A) and E9.5 (B) Wnt1-Cre/+; $Z / A P /+$ embryos. A sagittal section is shown in $B$. Neural crest cells, in which Cre-mediated recombination took place, appear blue/purple (arrow in $A$ ). Schematic presentation of Cre-mediated recombination of $F g f r 1^{f l o x}(F)$ and $F g f r 1^{n 7}(J)$ alleles is shown. Sagittal $(C, G)$ and transverse $(D, H)$ sections of E9.5 wild-type $(C, D)$ and Wnt1-Cre/+; Fgfr1 flox/flox $(G, H)$ embryos, hybridized with a Fgfr1 probe containing sequences from the region deleted by Cre. Note that the signal is present in the mesodermal core but is missing in neural crest cells of Wnt1-Cre/+; Fgfr1 flox/flox embryos (arrows in G,H). (K) Bright-field side view of E9.5 Wnt1-Cre/+; Fgfr1 $1^{n 7 / n 7}$ embryo. Arrow points to the aplastic second branchial arch. Ventral views of the skulls of newborn wild type $(E)$, Wnt1-Cre/+; Fgfr $1^{\text {flox } / \text { flox }}(I)$ and Wnt1-Cre/+; Fgfr ${ }^{n 7 / n 7}(L)$ mice stained with Alizarin Red and Alcian Blue. BA1, first branchial arch; BA2, second branchial arch; M, mesoderm; NCC, neural crest cells; PL, palatine; T, tympanic ring.

crest cells. To distinguish between these possibilities, we analyzed epithelial patterning at an early stage of second branchial arch formation. At 8-somite stage, Fgf3 is normally expressed in rhombomeres 5 and 6 as well as the ectoderm overlying the second branchial arch (Fig. 9A,C; Mahmood et al. 1996). The early ectodermal domain of Fgf3 expression was found to be down-regulated in $F_{g} f r^{n 7 / n 7}$ mutants (Fig. 9B,D). At the same stage, pattern of expression of the neural crest marker Crabp1 is strikingly similar in $F g f r 1^{n 7 / n 7}$ hypomorphs (Fig. 9F,H) and wild-type embryos (Fig. 9E,G). Neural crest migration defects in hypomorphs appear at 10-somite stage, the stage when neural crest cells normally start to populate the second branchial arch (data not shown). Our results show that gene-expression in the ectoderm is affected before the neural crest cell migration defect in the Fgfr $1^{n 7 / n 7}$ hypomorphs.

\section{Discussion}

Development of the vertebrate branchial arches is regulated at several stages. Both global and local patterning events are involved and different cellular populations participate in the branchial arch development. Neural crest cells give rise to the patterned skeletal derivatives of the branchial arches. The skeletal elements largely instruct development of other pharyngeal tissues, including the muscles. Therefore, a lot of emphasis in the research on craniofacial development has been put on the neural crest. Nonneural crest cell types, however, have been shown recently to have important roles in controlling the fate of neural crest cells. Despite their importance, very little is known about the mechanisms, which regulate the regional characteristics of the pharyngeal components other than neural crest.

We have here analyzed the role of one of the FGF receptors, Fgfr1, during the development of the pharyngeal region. Using a hypomorphic Fgfr1 allele, we demonstrate that perturbation of Fgfr1 function leads into a failure in neural crest cell entry into the second branchial arch. This defect does not, however, appear to reflect a neural-crest-cell-specific function of Fgfr1. Instead, our results indicate that signaling through FGFR1 patterns the pharyngeal region and creates a permissive environment for neural crest migration into the second branchial arch.

Second branchial-arch-specific defects, superficially similar to the ones in the hypomorphic Fgfr1 mutants, are also seen in mice defective for Hoxa1 and Hoxb1. FGF signaling has been implicated in the antero-posterior patterning of the neurectoderm as well as mesoderm (Doniach 1995; Partanen et al. 1998; Pownall et al. 1998). 

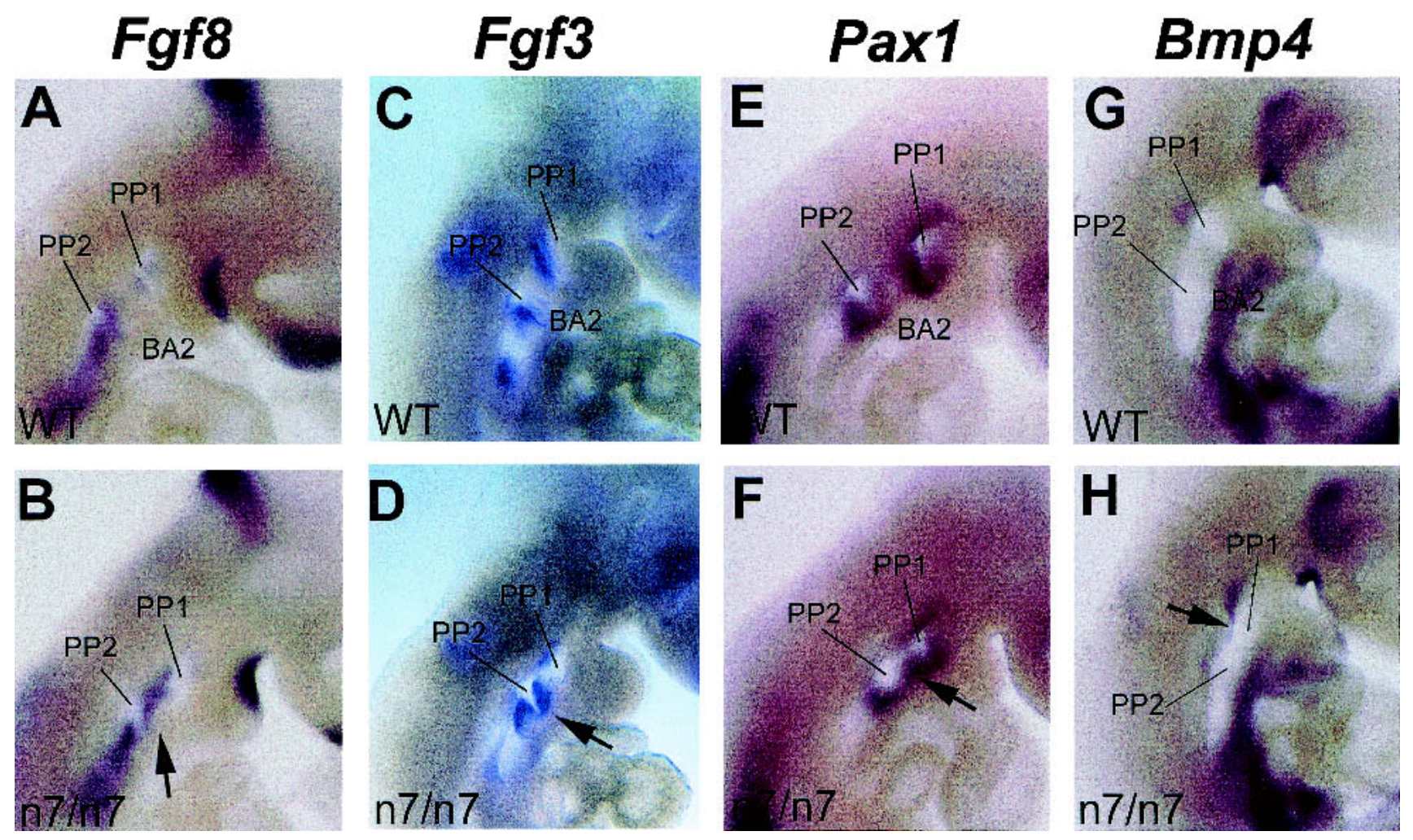

Figure 8. Expression of epithelial markers of the second branchial arch is affected in $F g f r 1^{n 7 / n 7}$ hypomorphs. Whole-mount in situ analysis of Fgf8 $(A, B), F f g 3(C, D), P a x 1(E, F)$ and Bmp4 $(G, H)$ expression at E9. Expression of $F g f 8$ and $F g f 3$ in pharyngeal clefts and pouches as well as Pax1and Bmp4 in pharyngeal pouches is affected in $F g f r 1^{n 7 / n 7}$ embryos specifically in the region of the proximal second branchial arch (arrows in $B, D, F, H)$ compared with the wild-type controls $(A, C, E, G)$. BA2, second branchial arch; PP1, First pharyngeal pouch; PP2, second pharyngeal pouch.

Our results, however, indicate that the branchial arch defects seen in our hypomorphs do not result from abnormal segmentation or patterning of the hindbrain. Also, the initial production of neural crest appears normal in the hypomorphic Fgfr1 mutants.

Our results with the neural crest markers provided first insights into the cellular process affected in the Fgfr $1^{n 7 / n 7}$ mutants. It appears that the neural crest of the second arch initially forms normally, migrates ventrally, but then fails to enter the second branchial arch. As a result, excessive neural crest cells are seen anterior to the otic vesicle in the mutants. Initially, the block in the neural crest cell entry to the second branchial arch is not complete, but later the stream of neural crest appears discontinuous and the distal part of the arch is separated from the dorsal pharyngeal region. Because of this physical separation, there does not appear to be delayed neural crest migration into the second branchial arch at later stages in the mutants. The cells that colonize the distal arch are able to pattern correctly, presumably in response to local signals. They also form some of the mature second arch structures, such as the lesser horns of the hyoid bone. Instead, the proximal second branchial arch fails to develop and skeletal elements derived from the proximal second arch, such as the styloid process (Kontges and Lumsden 1996), are always affected. This may reflect a later requirement for FGF signaling in the survival or proliferation of the neural crest cells of the proximal second arch. Alternatively, it is possible that the reduced neural crest cells are not evenly distributed in the second branchial arch of the $F g f r 1^{n 7 / n 7}$ embryos, but primarily colonize the distal region. As a result, there may simply be too few neural crest cells to support the development of the proximal arch. Consistent with the latter possibility, early migrating neural crest cells are known to colonize the distal arches whereas later migrating cells contribute to the proximal arch regions (Serbedzija et al. 1992).

FGFs have been reported to induce cellular migration in various developmental processes (Ciruna et al. 1997; Metzger and Krasnow 1999). Consistent with a possible role in neural crest cell guidance, FGF2 and FGF8 have been shown recently to induce chemotactic migration of mesencephalic neural crest cells (Kubota and Ito 2000). We therefore used two experimental strategies to test whether the FGFs expressed in the branchial arch epithelia directly attract the neural crest cells into the arch through activation of FGFR1. Neural crest cell specific mutation of Fgfr1 did not result in defects in the early second branchial arch development. Consistently, conversion of the hypomorphic Fgfr1 allele into a wild-type allele in the neural crest cells could not rescue the sec- 


\section{Fgf3}
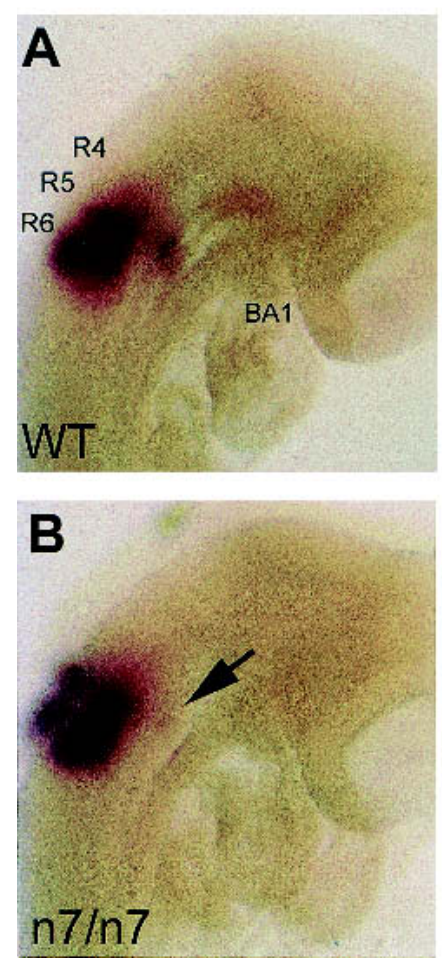
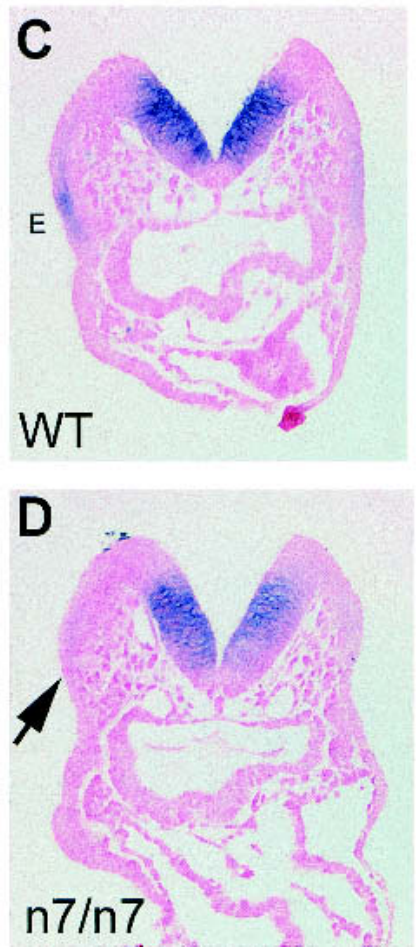

Crabp1
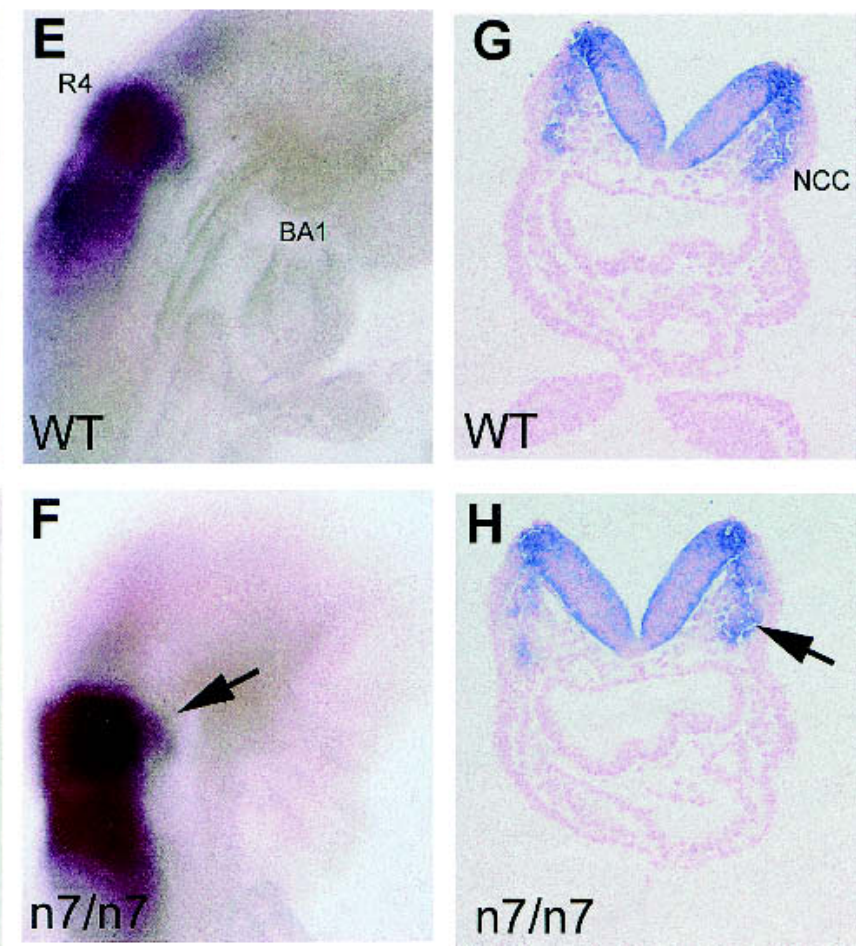

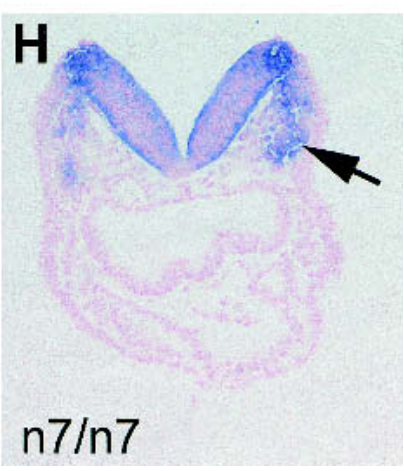

Figure 9. Fgf3 expression in the presumptive second branchial arch ectoderm is altered before neural crest cell migration defect in $F g f r 1^{n 7 / n 7}$ embryos. Fgf3 and Crabp1 expression in wild-type $(A, C, E, G)$ and $F g f r 1^{n 7 / n 7}(B, D, F, H)$ embryos at 8 -somite stage. Expression of Fgf3 in ectoderm overlying the second branchial arch $(A, C)$ is down-regulated in $F g f r 1^{n 7 / n 7}$ mutants $($ arrows in $B, D)$. At the same stage, Crabp1 expression in neural crest cells is similar in wild-type $(E, G)$ and $F g f r 1^{n 7 / n 7}(F, H)$ embryos.

ond branchial arch development. Therefore, Fgfr1 does not appear to have an essential neural crest cell autonomous function during the early development of the second branchial arch. Interestingly, other defects observed in hypomorphic Fgfr1 mice, such as facial clefting, were enhanced in the neural-crest-specific Fgfr1 mutants. These defects were also rescued by conversion of the hypomorphic Fgfr1 allele back to wild type in neural crest cells. These results suggest additional neural crest specific functions for Fgfr1.

Neural crest cells delaminate from the rhombomere 4 at 5-7-somite stage and start entering second branchial arch at 10-somite stage. Down-regulation of Fgf3 expression specifically in the ectoderm covering the presumptive second branchial arch was detected in the Fgfr1 hypomorphs already at 8 -somite stage. This was followed by significantly decreased influx of neural crest cells into the second branchial arch of hypomorphs already at 10somite stage. Therefore, Fgf3 expression in the ectoderm is down-regulated prior to defect in neural crest migration, and it is possible that the defect in ectodermal patterning results in the observed failure in neural crest cell migration in Fgfr1 hypomorphs. Signals from the ectoderm, including Fgf3, might act directly on neural crest cells to guide their migration. Our results, however, with conditional rescue and inactivation of $F g f r 1$, indicate that these signals are not received by FGFR1 on the neu- ral crest cells. Alternatively, correct ectodermal patterning might be required for interaction between ectoderm and endoderm to generate a structure, which allows neural crest migration into the second branchial arch. Consistent with this proposal are observations that the first and second pharyngeal pouches form before influx of neural crest into the second branchial arch and that they are formed and patterned correctly also after neural crest cell ablation (Veitch et al. 1999). Also, it has been proposed that FGF signaling can regulate GATA gene expression in broad antero-posterior domains of nonneural ectoderm (Read et al. 1998). Our data indicate that Fgfr1 defines characteristics of even more restricted ectodermal regions possibly analogous to the "ectomeres" associated with specific branchial arches (Couly and Le Douarin 1990).

Defects in hypomorphic Fgfr1 mutants were seen specifically in the proximal second branchial arch, whereas early development of the other arches appeared morphologically less affected. The second arch specificity of the early arch disruption is compatible with the suggested patterning defect in the pharyngeal region. In contrast to the early branchial arch development, skeletal preparations of newborn mutants revealed abnormalities also in several first-arch-derived skeletal elements. Fgfr1 may therefore also have a function in the development of the other arches as well. This would be consistent with ex- 
pression of both Fgfr1 and Fgfs in all of the branchial arches.

Alternatively, some of the first arch defects may be indirect. A patterning center has been proposed to exist between the first and second branchial arch (Rijli et al. 1993). Abnormal development of the second arch may disrupt such a center leading secondarily to first arch defects. Altered expression of epithelial signaling molecules may also contribute to the second arch defects. For example, expression of $B m p 4$ was expanded to partially include the second arch region. As BMPs have been suggested to induce apoptosis in cranial neural crest, the expanded Bmp4 expression could contribute to the apoptotic death of cells failing to enter the second arch.

Defects in skeletal elements derived from proximal arches have also been found in Dlx1 and Dlx2 mutants (Qiu et al. 1995). In contrast to Fgfr $1^{n 7 / n 7}$ embryos, the initial formation of the branchial arches appears rather undisturbed in the Dlx mutants. In E9.5 Fgfr $1^{n 7 / n 7}$ embryos, a correct set of $D l x$ genes were expressed in the proximal region of the second branchial arch. Therefore, the early proximo-distal patterning of the second arch neural crest appears unaltered in the $F g f r 1^{n 7 / n 7}$ mutants. Later, Dlx2 expression was not detected anymore in the proximal region. This may be attributable to altered signaling from the pharyngeal epithelia or elimination of neural crest cells in the proximal region.

It has been demonstrated previously that specific inactivation of the $F g f 8$ gene in the epithelium of the first branchial arch leads to extensive apoptosis in the first arch neural crest (Trumpp et al. 1999). Somewhat similar to our Fgfr1 hypomorphs, the defects appeared specific for the proximal region of the branchial arch, whereas the development of the most distal arch was less affected. Therefore, it appears that the proximal and distal parts of the branchial arches are regulated by different mechanisms. Unlike in the $F g f r 1^{n 7 / n 7}$ embryos, migration of neural crest cells is unaffected in the embryos lacking Fgf8 in the first-branchial arch epithelium. Increased neural crest cell apoptosis was also observed in the $F g f r 1^{n 7 / n 7}$ embryos. In contrast to the Fgf8 mutants described above, however, no increase in apoptotic cells was observed in the branchial arch itself, but in the region proximal to the arch in $F g f r 1^{n 7 / n 7}$ embryos. This region overlaps with the site where neural crest cells were found to accumulate. Therefore, it is possible that the cell death in the $F g f r 1^{n 7 / n 7}$ embryos is secondary to a failure of neural crest cells to correctly enter the second branchial arch or a defect in epithelial patterning (see above). It is also possible that Fgfr2, which, also, is expressed in the neural crest of the branchial arches (see Supplemental Material), mediates effects of Fgf8, perhaps together with Fgfr1.

In summary, two patterning processes, neural-crest-dependent and neural-crest-independent, have been suggested to regulate development of the pharyngeal region. Our results indicate that signaling through FGFR1 is essential for the neural-crest-independent patterning of the pharyngeal ectoderm. Defect in this process is subsequently reflected in abnormal behavior of the neural crest cells.

\section{Materials and methods}

\section{Mice and genotyping}

Analyses of mice carrying hypomorphic $\left(F g f r 1^{n 7}\right.$; Partanen et al. 1998) and conditional (Fgfr ${ }^{\text {flox }}$; R. Trokovic, N. Trokovic, S. Hernesniemi, U. Pirvola, J. Rossant, A.P. McMahon, W. Wurst, and J. Partanen, in prep.) Fgfr1 alleles as well as the Tie ${ }^{1 c Z}$ allele (Puri et al. 1995) and Wnt1-Cre (Danielian et al. 1998) and Z/AP (Lobe et al. 1999) transgenes were carried out in outbred (ICR) background. Embryonic age was estimated by counting the somites or considering noon of the day of a vaginal plug as E0.5.

Mice and embryos were genotyped by PCR analysis of DNA prepared from tail biopsies and yolk sacs, respectively. Oligonucleotide primers used for detection of the wild-type Fgfr1 allele were upstream 5'-CCCCATCCCATTTCCTTACCT-3' and downstream 5'-TTCTGGTGTGTCTGAAAACAGCT-3' (145-bp product). $F g f r 1^{n 7}$ and $F g f r^{\text {flox }}$ alleles were detected by upstream 5'-AATAGGTCCCTCGACGGTATC-3' and downstream 5'-CTGGGTCAGTGTGGACAGTGT-3' primers (166bp product). The primers used for detecting Wnt1-Cre gene were 5'-ATTCTCCCACCGTCAGTACG-3' and 5'-CGTTTTCTGAG CATACCTGGA-3'.

\section{Skeletal analysis}

For whole-mount analysis of skeletons, newborn mice were eviscerated and fixed in $95 \%$ ethanol overnight. After removing skin, the preparations were incubated in Alcian Blue stain (1 vol. of glacial acetic acid, 4 vol. of $95 \%$ ethanol containing 0.15 $\mathrm{mg} / \mathrm{mL}$ of Alcian Blue, Sigma A3157) for 24-48 h. The preparations were rinsed in $95 \%$ ethanol for $1 \mathrm{~h}$, after which they were incubated in 2\% KOH for 12-24 h and in Alizarin Red stain (1\% $\mathrm{KOH}$ with $75 \mu \mathrm{g} / \mathrm{mL}$ Alizarin Red-S, Sigma A5533) for 12-24 h. The preparations were cleared in $20 \%$ glycerol, $1 \% \mathrm{KOH}$ for one week and then transferred to $50 \%$ glycerol, $50 \%$ ethanol for photography and storage.

\section{Scanning electron microscopy}

Embryos were dissected in PBS, fixed overnight at $4^{\circ} \mathrm{C}$ in $4 \%$ paraformaldehyde (PFA) in PBS, dehydrated through a graded series of ethanol $\left(50 \%, 70 \%, 94 \%, 100 \%\right.$ in $\left.\mathrm{ddH}_{2} \mathrm{O}\right)$ for $5,10,20$ and $45 \mathrm{~min}$, respectively, and dried with a critical-point drying apparatus. Embryos were mounted on aluminium stubs and coated with platinum before photographing with a DSM -962 scanning electron microscope (ZEISS).

\section{Analyses of cell death}

Nile Blue Sulfate (NBS) staining: Following dissection, embryos (E9, E9.5) were washed in PBS, and incubated for $30 \mathrm{~min}$. at $37^{\circ} \mathrm{C}$ in filtered, NBS- (Sigma N-5632) saturated water diluted 1:1000 in PBT (PBS containing 0.1\% Tween-20). Embryos were then washed several times in PBT at room temperature and photographed immediately.

TUNEL analysis: TUNEL assays were performed on paraffin sections with Fluorescein In Situ Cell Death Detection Kit (Boehringer Mannheim, Mannheim, Germany) according to manufacturer's instructions. Sections were counterstained with 4', 6-diamidino-2-phenylindole (DAPI) nuclear stain. 


\section{Whole-mount mRNA in situ hybridization}

Whole-mount mRNA in situ hybridization with Ap2, Bmp4, Crabp1 (IMAGE468821), Dlx1，Dlx2, Dlx5, EphA4, EphB2 (IMAGE 4983886), EphB3 (IMAGE 1110951), Fgf3, Fgf8, Pax1 (IMAGE 1327502), Hoxa2, Hoxd4, Hoxb1, Hoxb2, Krox20, and Msx1 probes was performed as described (Henrique et al. 1995). For sectioning of whole-mount in situ hybridization stained embryos, samples were washed in PBS, dehydrated through the methanol series, embedded in paraffin, and sectioned at $5 \mu \mathrm{m}$ in the transverse or sagittal plane. Sections were counter-stained with eosin.

\section{In situ hybridization on sections}

A fragment of Fgfr1 cDNA containing exonic sequences from the region deleted by Cre-mediated recombination (nucleotides 1152-1724 of GenBank accession no. NM010206) as well as fragments of Fgfr2 and Fgfr3 cDNAs were used as probes. In situ hybridization on paraffin-embedded tissue sections was performed using $\left[{ }^{35} \mathrm{~S}\right]$-UTP-labeled riboprobes as described (Wilkinson and Green 1990). Following in situ hybridization, the sections were stained with Delafield's hematoxylin and mounted with DePeX (BDG).

\section{Whole-mount alkaline phosphatase and} $\beta$-galactosidase staining

Whole-mount alkaline phosphatase and $\beta$-galactosidase staining of E8.5-E9.5 embryos were performed as described previously (Lobe et al. 1999).

\section{Acknowledgments}

We thank Eija Koivunen, Päivi Hannuksela, and Mervi Lindahl for expert technical assistance; Andrew McMahon for Wnt1-Cre mice; Andras Nagy for Z/AP mice; Ulla Pirvola for help with apoptosis assays; and Moises Mallo for discussions. We also thank the following persons for providing us with cDNA probes: Pierre Chambon (Hoxb2); Patric Charnay (Krox20); Phil Crossley $(F g f 8)$; Duncan Davidson (Msx1); Mark Featherstone (Hoxd4); Robb Krumlauf (Hoxb1); Suzanne Mansour (Fgf3); Alka Mansukhani (Fgfr2); Pamela Mitchell (Ap2); Kevin Peters (Fgfr3); John Rubenstein (Dlx1, Dlx2, and Dlx5) and Paul Sharpe (Bmp4). This work was supported by the Academy of Finland, Sigrid Juselius foundation and Biocentrum Helsinki. N.T. is supported by the Viikki Graduate School, University of Helsinki.

The publication costs of this article were defrayed in part by payment of page charges. This article must therefore be hereby marked "advertisement" in accordance with 18 USC section 1734 solely to indicate this fact.

\section{References}

Ciruna, B.G., Schwartz, L., Harpal, K., Yamaguchi, T.P., and Rossant, J. 1997. Chimeric analysis of fibroblast growth factor receptor-1 (Fgfr1) function: a role for FGFR1 in morphogenetic movement through the primitive streak. Development 124: 2829-2841.

Couly, G. and Le Douarin, N.M. 1990. Head morphogenesis in embryonic avian chimeras: evidence for a segmental pattern in the ectoderm corresponding to the neuromeres. Development 108: 543-558.
Couly, G., Creuzet, S., Bennaceur, S., Vincent, C., and Le Douarin, N.M. 2002. Interactions between Hox-negative cephalic neural crest cells and the foregut endoderm in patterning the facial skeleton in the vertebrate head. Development 129: 1061-1073.

Crossley, P.H. and Martin, G.R. 1995. The mouse Fgf8 gene encodes a family of polypeptides and is expressed in regions that direct outgrowth and patterning in the developing embryo. Development 121: 439-451.

Danielian, P.S., Muccino, D., Rowitch, D.H., Michael, S.K., and McMahon, A.P. 1998. Modification of gene activity in mouse embryos in utero by a tamoxifen-inducible form of Cre recombinase. Curr. Biol. 8: 1323-1326.

Deng, C.X., Wynshaw-Boris, A., Shen, M.M., Daugherty, C., Ornitz, D.M., and Leder, P. 1994. Murine FGFR-1 is required for early postimplantation growth and axial organization. Genes \& Dev. 8: 3045-3057.

Doniach, T. 1995. Basic FGF as an inducer of anteroposterior neural pattern. Cell 83: 1067-1070.

Ferguson, C.A., Tucker, A.S., and Sharpe, P.T. 2000. Temporospatial cell interactions regulating mandibular and maxillary arch patterning. Development 127: 403-412.

Francis-West, P., Ladher, R., Barlow, A., and Graveson, A. 1998. Signalling interactions during facial development. Mech. Dev. 75: 3-28.

Gavalas, A., Studer, M., Lumsden, A., Rijli, F.M., Krumlauf, R., and Chambon, P. 1998. Hoxal and Hoxb1 synergize in patterning the hindbrain, cranial nerves and second pharyngeal arch. Development 125: 1123-1136.

Graham, A. 2001. The development and evolution of the pharyngeal arches. J. Anat. 199: 133-141.

Heikinheimo, M., Lawshe, A., Shackleford, G.M., Wilson, D.B., and MacArthur, C.A. 1994. Fgf-8 expression in the post-gastrulation mouse suggests roles in the development of the face, limbs and central nervous system. Mech. Dev. 48: 129138.

Henrique, D., Adam, J., Myat, A., Chitnis, A., Lewis, J., and Ish-Horowicz, D. 1995. Expression of a Delta homologue in prospective neurons in the chick. Nature 375: 787-790.

Kontges, G. and Lumsden, A. 1996. Rhombencephalic neural crest segmentation is preserved throughout craniofacial ontogeny. Development 122: 3229-3242.

Kubota, Y. and Ito, K. 2000. Chemotactic migration of mesencephalic neural crest cells in the mouse. Dev. Dyn. 217: 170179 .

Lobe, C.G., Koop, K.E., Kreppner, W., Lomeli, H., Gertsenstein, M., and Nagy, A. 1999. Z/AP, a double reporter for cre-mediated recombination. Dev. Biol. 208: 281-292.

Lumsden, A. and Krumlauf, R. 1996. Patterning the vertebrate neuraxis. Science 274: 1109-1115.

Maconochie, M., Krishnamurthy, R., Nonchev, S., Meier, P., Manzanares, M., Mitchell, P.J., and Krumlauf, R. 1999. Regulation of Hoxa2 in cranial neural crest cells involves members of the AP-2 family. Development 126: 1483-1494.

Mahmood, R., Mason, I.J., and Morriss-Kay, G.M. 1996. Expression of Fgf-3 in relation to hindbrain segmentation, otic pit position and pharyngeal arch morphology in normal and retinoic acid- exposed mouse embryos. Anat. Embryol. (Berl) 194: $13-22$.

Metzger, R.J. and Krasnow, M.A. 1999. Genetic control of branching morphogenesis. Science 284: 1635-1639.

Muller, T.S., Ebensperger, C., Neubuser, A., Koseki, H., Balling, R., Christ, B., and Wilting, J. 1996. Expression of avian Paxl and $\operatorname{Pax} 9$ is intrinsically regulated in the pharyngeal endoderm, but depends on environmental influences in the paraxial mesoderm. Dev. Biol. 178: 403-417. 
Partanen, J., Schwartz, L., and Rossant, J. 1998. Opposite phenotypes of hypomorphic and Y766 phosphorylation site mutations reveal a function for Fgfrl in anteroposterior patterning of mouse embryos. Genes \& Dev. 12: 2332-2344.

Pownall, M.E., Isaacs, H.V., and Slack, J.M. 1998. Two phases of Hox gene regulation during early Xenopus development. Curr. Biol. 8: 673-676.

Puri, M.C., Rossant, J., Alitalo, K., Bernstein, A., and Partanen, J. 1995. The receptor tyrosine kinase TIE is required for integrity and survival of vascular endothelial cells. EMBO $I$. 14: 5884-5891.

Qiu, M., Bulfone, A., Martinez, S., Meneses, J.J., Shimamura, K., Pedersen, R.A., and Rubenstein, J.L.R. 1995. Null mutation of Dlx-2 results in abnormal morphogenesis of proximal first and second branchial arch derivatives and abnormal differentiation in the forebrain. Genes \& Dev. 9: 2523-2538.

Read, E.M., Rodaway, A.R., Neave, B., Brandon, N., Holder, N., Patient, R.K., and Walmsley, M.E. 1998. Evidence for nonaxial A/P patterning in the nonneural ectoderm of Xenopus and zebrafish pregastrula embryos. Int. J. Dev. Biol. 42: 763774.

Richman, J.M. and Tickle, C. 1989. Epithelia are interchangeable between facial primordia of chick embryos and morphogenesis is controlled by the mesenchyme. Dev. Biol. 136: $201-210$.

Rijli, F.M., Mark, M., Lakkaraju, S., Dierich, A., Dolle, P., and Chambon, P. 1993. A homeotic transformation is generated in the rostral branchial region of the head by disruption of Hoxa-2, which acts as a selector gene. Cell 75: 13331349.

Rijli, F.M., Gavalas, A., and Chambon, P. 1998. Segmentation and specification in the branchial region of the head: the role of the Hox selector genes. Int. J. Dev. Biol. 42: 393-401.

Serbedzija, G.N., Bronner-Fraser, M., and Fraser, S.E. 1992. Vital dye analysis of cranial neural crest cell migration in the mouse embryo. Development 116: 297-307.

Smith, A., Robinson, V., Patel, K., and Wilkinson, D.G. 1997. The EphA4 and EphB1 receptor tyrosine kinases and ephrinB2 ligand regulate targeted migration of branchial neural crest cells. Curr. Biol. 7: 561-570.

Trainor, P. and Krumlauf, R. 2000. Plasticity in mouse neural crest cells reveals a new patterning role for cranial mesoderm. Nat. Cell. Biol. 2: 96-102.

Trumpp, A., Depew, M.J., Rubenstein, J.L., Bishop, J.M., and Martin, G.R. 1999. Cre-mediated gene inactivation demonstrates that FGF8 is required for cell survival and patterning of the first branchial arch. Genes \& Dev. 13: 3136-3148.

Tucker, A.S., Al Khamis, A., Ferguson, C.A., Bach, I., Rosenfeld, M.G., and Sharpe, P.T. 1999. Conserved regulation of mesenchymal gene expression by Fgf- 8 in face and limb development. Development 126: 221-228.

Veitch, E., Begbie, J., Schilling, T.F., Smith, M.M., and Graham, A. 1999. Pharyngeal arch patterning in the absence of neural crest. Curr. Biol. 9: 1481-1484.

Wilke, T.A., Gubbels, S., Schwartz, J., and Richman, J.M. 1997. Expression of fibroblast growth factor receptors (FGFR1, FGFR2, FGFR3) in the developing head and face. Dev. Dyn. 210: $41-52$.

Wilkinson, D.G. and J. Green. 1990. In situ hybridization and the three-dimensional construction of serial sections. In Postimplantation mammalian embryos (eds. A.J. Copp and D.L. Cockroft), pp. 155-171. Oxford University Press: IRL.

Wilkinson, D.G., Peters, G., Dickson, C., and McMahon, A.P. 1988. Expression of the FGF-related proto-oncogene int-2 during gastrulation and neurulation in the mouse. $E M B O I$. 7: 691-695.
Yamaguchi, T.P., Conlon, R.A., and Rossant, J. 1992. Expression of the fibroblast growth factor receptor FGFR-1/flg during gastrulation and segmentation in the mouse embryo. Dev. Biol. 152: 75-88.

Yamaguchi, T.P., Harpal, K., Henkemeyer, M., and Rossant, J. 1994. fgfr-1 is required for embryonic growth and mesodermal patterning during mouse gastrulation. Genes \& Dev. 8: 3032-3044. 


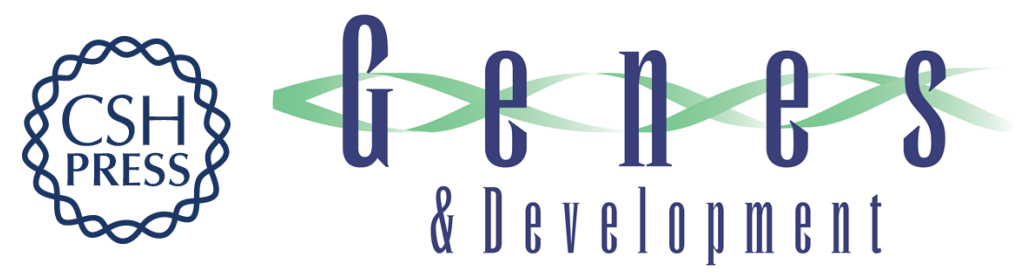

\section{Fgfr1 regulates patterning of the pharyngeal region}

Nina Trokovic, Ras Trokovic, Petra Mai, et al.

Genes Dev. 2003, 17:

Access the most recent version at doi:10.1101/gad.250703

Supplemental

Material

References This article cites 39 articles, 17 of which can be accessed free at: http://genesdev.cshlp.org/content/17/1/141.full.html\#ref-list-1

\section{License}

Email Alerting Service

http://genesdev.cshlp.org/content/suppl/2003/01/06/17.1.141.DC1 right corner of the article or click here.

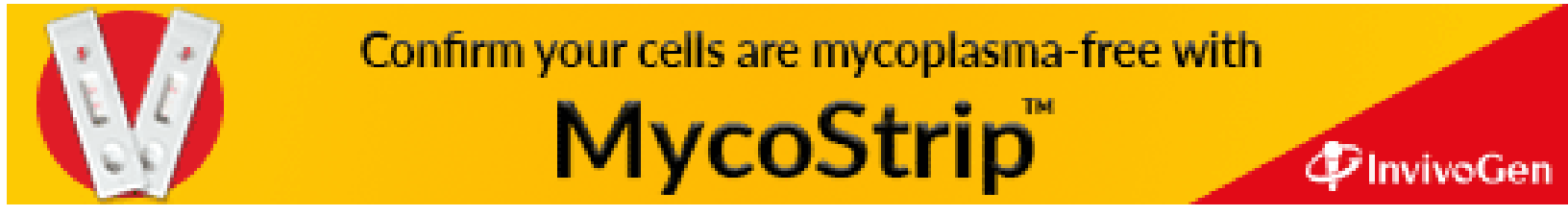

